\title{
Perceived Usefulness, Self-Efficacy, and Emotional Engagement: Does It Affect Student's Satisfaction while using the Platform?
}

\author{
Iffa Masruroh ${ }^{1}$, Jun Surjanti ${ }^{2}$, Ni'matush Sholikhah 3
}

DOI: $10.35445 /$ alishlah.v13i1. 536

\begin{tabular}{l}
\hline Article Info \\
\hline Keywords: \\
Perceived Usefulness \\
Self-Efficacy \\
Emotional Engagement \\
Student Satisfaction
\end{tabular}

Kata kunci:

Persepsi Usefulness

Self-Efficacy

Emotional Engagement

Kepuasan Siswa

\begin{abstract}
Many students are dissatisfied with using blended learning platforms. At the same time, student satisfaction with a blended learning platform can determine the quality of learning and learning outcomes. This study analyzed the direct and indirect influence between the user perception of a blended learning platform, self-efficacy, and emotional engagement on student satisfaction. This research includes quantitative research with a type of causality-grade XI students of IPS SMA 14 Negeri Surabaya as a population. A sample of 103 students was taken using saturated sample techniques. Data collection is obtained through interviews, questionnaires, and documentation. The data analysis used is path analysis. The results directly influenced perceptions of the usefulness of blended learning platforms, self-efficacy, and emotional engagement on student satisfaction. The indirect influence between the perception of usefulness of platform and selfefficacy to student satisfaction through emotional engagement.
\end{abstract}

\begin{abstract}
Abstrak
Banyak siswa merasa kurang puas dalam menggunakan platform blended learning. Sedangkan kepuasan siswa terhadap platform blended learning mampu menentukan kualitas pembelajaran dan hasil belajar. Penelitian ini menganalisis pengaruh secara langsung dan tidak langsung antara persepsi usefulness of platform blended learning, self-efficacy dan emotional engagement terhadap kepuasan siswa. Penelitian ini termasuk penelitian kuantitatif dengan jenis kausalitas. Siswa kelas XI IPS SMA 14 Negeri Surabaya sebagai populasi. Sampel berjumlah 103 siswa yang diambil menggunakan teknik sampel jenuh. Pengumpulan data diperoleh melalui wawancara, angket dan dokumentasi. Analisis data yang digunakan yaitu analisis jalur. Hasil penelitian menemukan pengaruh langsung antara persepsi usefulness of platform blended learning, self-efficacy dan emotional engagement terhadap kepuasan siswa. Serta pengaruh tidak langsung antara persepsi usefulness of platfrom dan self-efficacy terhadap kepuasan siswa melalui emotional engagement.
\end{abstract}

\footnotetext{
${ }^{1}$ Universitas Negeri Surabaya, Surabaya, Indonesia

Email: iffa.17080554042@mhs.unesa.ac.id

2 Universitas Negeri Surabaya, Surabaya, Indonesia

Email: junsurjanti@unesa.ac.id

3 Universitas Negeri Surabaya

Email: nimatushsholikhah@unesa.ac.id
} 


\section{PENDAHULUAN}

Pandemi Covid-19 telah mengubah tatanan kehidupan, salah satunya di bidang pendidikan yang mengakibatkan banyaknya transformasi. Namun tidak semua siswa mampu menyesuaikan adanya transformasi tersebut. Hasil survei yang dilakukan UNICEF menyatakan bahwa 66\% siswa mengalami ketidaknyamanan saat belajar di rumah dan sekitar 87\% ingin kembali belajar di sekolah (UNICEF, 2020).

Blended learning merupakan model pembelajaran yang banyak digunakan saat pandemi Covid19. Platform yang digunakan dalam blended learning termasuk Learning Management System (LMS). Platform dapat mendukung proses pembelajaran, mengelola konten pembelajaran dan memudahkan siswa untuk mengakses materi kapan saja dan dimana saja, serta dapat memudahkan dalam memantau perkembangan belajar siswa (Ohliati \& Abbas, 2019). Terdapat berbagai macam platform yang digunakan untuk menunjang kegiatan pembelajaran yaitu google classroom, goole meet, ruang guru, zoom dan lain sebagainya.

Penerimaan platform dalam pembelajaran ditunjukkan dengan kepuasaan siswa (Almarashdeh, 2016). Kepuasan siswa sangat penting karena menentukan kualitas pembelajaran dan hasil belajar siswa (Bolliger, Inan, \& Wasilik, 2014). Individu akan merasa puas ketika harapannya terpenuhi atau terlampaui (Ibrahim Abbas, 2018) dan (Xiao \& Wilkins, 2015). Kepuasan pengguna dijadikan sebagai indikator atau ukuran dari keberhasilan sistem informasi (Andrade, Miller, Kunz, \& Ratliff, 2019).

Berdasarkan observasi, diketahui guru ekonomi di SMA Negeri 14 Surabaya menerapkan pembelajaran dengan blended learning pada kombinasi antara jenis platform yang digunakan yaitu terdiri dari platform sinkron (google meet) dan asinkron (google classroom). Salah satu siswa kelas XI IPS menyatakan bahwa Ia kurang puas belajar Indeks Harga dan Inflasi menggunakan platform blended learning. Kemudian siswa tersebut mempunyai harapan bisa memahami materi Indeks Harga dan Inflasi. Namun fakta di lapangan, siswa tidak mampu memahami materi berupa angka atau hitunghitungan.

Faktor yang menentukan kepuasan siswa dalam menggunakan platform yaitu persepsi usefulness (Ohliati \& Abbas, 2019) dan self-efficacy (Islam \& Azad, 2015). Selain itu emotional engagement juga mampu mempengaruhi kepuasan siswa (Gao, Jiang, \& Tang, 2020). Sehingga dalam penelitian ini yang akan dikaji lebih lanjut terkait faktor kepuasan siswa dalam menggunakan platform blended learning yaitu emotional engagement, persepsi usefulness of platform blended learning dan self-efficacy.

Kepuasan siswa dan engagement merupakan kontruksi yang kompleks karena keduanya memiliki hubungan yang sangat erat (Sahni, 2019). Emotional engagement diartikan sebagai respon afektif siswa di kelas yang meliputi kecemasan, kesedihan, kebahagiaan, kebosanan dan minat siswa (Skinner \& Belmont, 1993). Terdapat emotional engagement positif dan emotional engagement negatif (Halverson \& Graham, 2019). Emotional engagement berpengaruh terhadap kepuasan siswa (Bailey \& Morais, 2005); (Filak \& Sheldon, 2008); (Gao et al., 2020) dan (Sahni, 2019). Selain itu, model D\&M yang telah dimodifikasi oleh (Seddon, 1997) menemukan salah satu faktor yang mempengaruhi kepuasan siswa yaitu persepsi usefulness. Seiring berjalannya waktu banyak penelitian yang menemukan persepsi usefulness berpengaruh positif terhadap kepuasan pengguna (Al-Azawei, Parslow, \& Lundqvist, 2017); (Ghazal, Aldowah, Umar, \& Bervell, 2018); (Wu \& Liu, 2013); (Jung, Choi, Lim, \& Leem, 2002); (Prifti, 2020) dan (Chen \& Tat Yao, 2016) dan kepuasaan pengguna berpengaruh positif terhadap keberlanjutan penggunaan sistem (Lin et al., 2017) dan (Surjanti, Sakti, \& Fitrayati, 2020). Namun dalam penelitian lain menemukan persepsi usefulness tidak berpengaruh langsung terhadap kepuasan siswa, tetapi melalui emotional engagement (Gao et al., 2020).

Berdasarkan Teori Kognitif Sosial yang dikemukakan oleh Bandura dikembangkan menjadi model computer self-efficacy. Bandura mengemukakan bahwa self-efficacy yang dimiliki seseorang menjadi penentu dalam mempengaruhi perilaku dan motivasi yang dimiliki seseorang (Igbaria \& Iivari, 1995). Self-efficacy merupakan kemampuan diri dalam penggunaan komputer untuk menyelesaikan tugas yang sesuai dengan pendapat Compeau \& Higgins (Ghazal et al., 2018). Self-efficacy memiliki pengaruh positif terhadap kepuasan siswa (Ghazal et al., 2018); (Prifti, 2020) dan (Wolverton, Guidry 
Hollier, \& Lanier, 2020). Namun dari hasil penelitian lain ditemukan tidak adanya pengaruh selfefficacy terhadap kepuasan siswa (Eom, 2014) dan (Kuo, Walker, Belland, Schroder, \& Kuo, 2014). Selain itu self-efficacy juga menunjukkan bahwa terdapat pengaruhnya terhadap emotional engagement (Pellas, 2014) dan (Sahni, 2019).

Penelitian sebelumnya yang dilaksanakan oleh (Gao et al., 2020) berfokus pada pengaruh persepsi platform pada blended learning, engagement dan kepuasan siswa. Namun dalam penelitian ini hanya mempertimbangkan persepsi pada platform blended learning. Sedangkan dalam penggunaan platfrom blended learning banyak faktor yang perlu diperhatikan seperti faktor dari diri siswa, guru dan desain dari platform yang digunakan. Dalam penelitian ini mencoba untuk menyelidiki faktor dari diri siswa yaitu self-efficacy. Sehingga penelitian ini diharapkan mampu melengkapi penelitian terdahulu.

Maka dari itu penelitian ini perlu dilakukan untuk mengkaji lebih lanjut terkait pengaruh langsung antara persepsi usefulness of platform blended learning dan self-efficacy terhadap kepuasan siswa pada kelas XI IPS SMA Negeri 14 Surabaya. Pengaruh tidak langsung persepsi usefulness of platfrom terhadap kepuasan siswa yang dimediasi emotional engagement. Serta pengaruh tidak langsung self-efficacy terhadap kepuasan siswa yang dimediasi oleh emotional engagement yang menjadi pembaruan dalam penelitian ini. Hasil penelitian ini berkontribusi untuk mengetahui kepuasan siswa yang nantinya diharapkan mampu mempengaruhi keberhasilan pembelajaran.

\section{METODE}

Pendekatan yang digunakan dalam penelitian ini yaitu pendekatan kuantitatif dengan jenis kausalitas. Populasi berjumlah 103 siswa yang terdiri dari siswa kelas XI IPS 1, 2 dan 3 di SMA Negeri 14 Surabaya yang telah melaksanakan pembelajaran blended learning dengan menggunakan perpaduan platform sinkron (google meet) dan asinkron (google classroom). Sampel ditentukan dengan teknik non-probability sampling yaitu sampel jenuh yang merupakan teknik dalam pengambilan sampel dengan menggunakan keseluruhan populasi. Namun terdapat 21 siswa yang nonrespon sehingga data yang diolah berjumlah 82 siswa.

Penelitian ini membutuhkan waktu selama 4 bulan dimulai dari bulan November 2020 - Februari 2021. Data diperoleh melalui dokumentasi, wawancara dan angket. Angket yang disebarkan berupa angket tertutup yang berisi seperangkat pertanyaan dan disertai sejumlah jawaban alternatif sehingga responden hanya memilih jawabannya. Pengukuran angket menggunakan skala linkert dengan skala 14 dimulai dari yang terkecil yaitu sangat tidak setuju, tidak setuju, setuju dan yang skala yang terbesar yaitu sangat setuju. Wawancara dilakukan secara tidak langsung melalui WhatsApp. Sedangkan dokumentasi diperoleh dari data siswa. Instrumen yang digunakan mengadopsi dari penelitian terdahulu dengan jumlah 19 item yang terdiri dari 6 item untuk persepsi usefulness of platform blended learning dengan indikator kinerja belajar, bekerja lebih cepat, efektivitas, meningkatkan produktivitas, membuat belajar lebih mudah dan berguna (Davis, 1989). Self-efficacy terdiri dari 5 item dengan indikator magnitude, strength dan generalizatibility (Compeau \& Higgins, 1995). Emotional engagement yang terdiri dari 5 item dengan indikator menikmati pembelajaran, menarik, melakukan sesuatu dan merasa senang (Manwaring, 2017) dan 4 item untuk kepuasan siswa dengan indikator kepuasan, kebutuhan belajar terpenuhi, kesenangan dan merekomendasikan ke orang lain (Gao et al., 2020). Metode analisis data yang digunakan untuk mengolah data dalam penelitian ini yaitu analisis jalur dengan program SmartPLS 3.3. Pengujian data dalam penelitian ini dilaksanakan dengan mengevaluasi model pengukuran (outer model) dan model struktural (inner model). Pengujian outer model dengan menilai convergent validity, discriminant validity dan cronbach's alpha dan composite realibility. Sementara Inner Model dengan menilai $R$-Square, Standardized Root Mean Square Residual (SRMR), Q-Square dan Pengujian hipotesis. 


\section{HASIL PENELITIAN DAN PEMBAHASAN}

\section{Gambaran umum responden}

Penelitian ini bertujuan untuk mengkaji pengaruh secara langsung dan tidak langsung antara persepsi usefulness of platform blended learning, self-efficacy dan emotional engagement terhadap kepuasan siswa. Penelitian ini berfokus pada platform yang digunakan dalam blended learning. Sampel dari penelitian ini yaitu siswa kelas XI IPS 1, XI IPS 2 dan XI IPS 3 di SMA Negeri 14 Surabaya yang berjumlah 82 siswa. Responden laki-laki berjumlah 36 siswa atau 44\% dari sampel. Sedangkan responden perempuan berjumlah 46 siswa atau 56\% dari sampel. Berdasarkan data sampel diperoleh rata-rata siswa yaitu sebesar $71 \%$ menggunakan platform blended learning selama kurang dari satu tahun, 28\% menggunakan platform blended learning rentang 1-3 tahun dan 1\% lebih dari tiga tahun.

\section{Hasil Pengukuran Model atau Evaluasi Outer Model}

Convergent validity

Convergent validity merupakan nilai yang menunjukkan variabel manifes saling berkorelasi untuk mengukur konstruk laten. Convergent validity dapat diketahui dengan melihat nilai outer loading dan Average Variance Expected (AVE) dari hasil pengolahan data. Indikator dapat dinyatakan valid apabila dalam confirmatory research memiliki nilai outer loading $\geq 0.70$ dan $\geq 0.60$ untuk explanatory research. Namun pendapat dari (Ghozali \& Latan, 2012) yang mengutip pernyataan dari Chin bahwa outer loading sudah dianggap cukup apabila nilainya $\geq 0.50$.

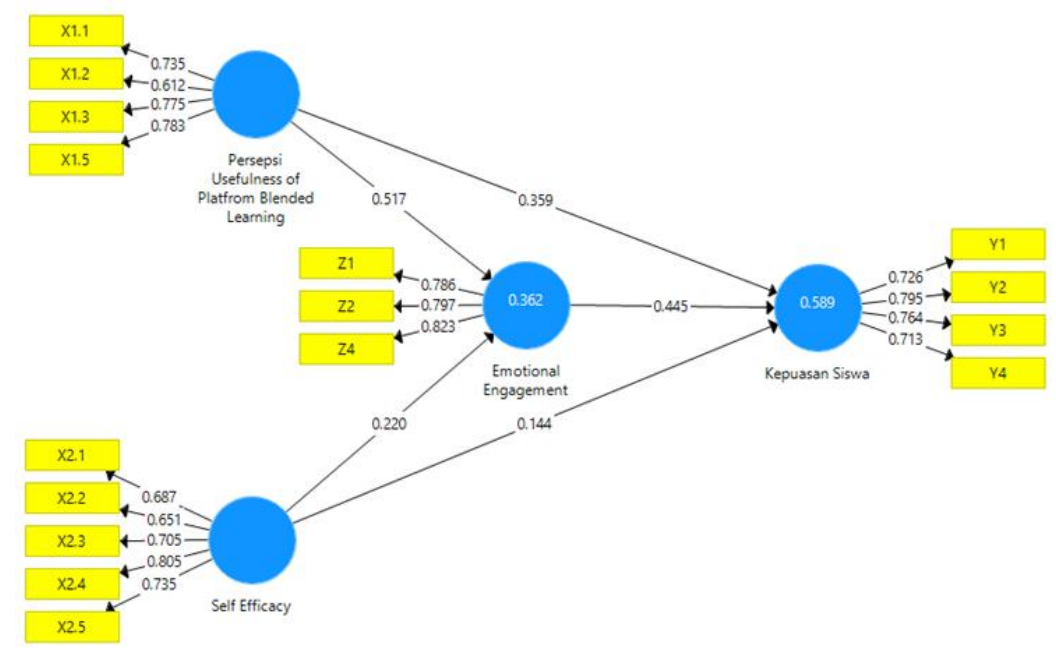

\section{Gambar. 1. Hasil outer model}

Pada penelitian ini sesuai dengan pendapat Chin dalam (Ghozali \& Latan, 2012) yang menggunakan standart nilai dari outer loading yaitu $\geq 0.50$. Terdapat 3 item dari 19 item yang mempunyai nilai outer loading $\geq 0.50$, sehingga item tersebut harus dihapus dari model. Penghapusan dari item yang dibawah 0.50 perlu dilakukan agar tidak mempengaruhi penurunan nilai AVE

Selain itu convergent validity dapat dilihat dari nilai AVE. Berikut merupakan hasil dari convergent validity yang menunjukkan hasil outer loading dan AVE :

Tabel 1. Hasil Outer Loading dan AVE

\begin{tabular}{|c|c|c|c|}
\hline Variabel & Item & $\begin{array}{l}\text { Outer } \\
\text { Loading }\end{array}$ & $\begin{array}{l}\text { Average Variance } \\
\text { Expected (AVE) }\end{array}$ \\
\hline Persepsi Usefulness of & $\mathrm{X} 1.1$ & 0,735 & 0,532 \\
\hline \multirow{3}{*}{ Platfrom } & $\mathrm{X} 1.2$ & 0,612 & \\
\hline & $\mathrm{X} 1.3$ & 0,775 & \\
\hline & $\mathrm{X} 1.5$ & 0,783 & \\
\hline \multirow[t]{6}{*}{ Self-Efficacy } & $\mathrm{X} 2.1$ & 0,687 & 0.516 \\
\hline & $\mathrm{X} 2.2$ & 0,651 & \\
\hline & $\mathrm{X} 2.3$ & 0,705 & \\
\hline & $\mathrm{X} 2.4$ & 0,805 & \\
\hline & $\mathrm{X} 2.5$ & 0,735 & \\
\hline & Pag & 629 & \\
\hline
\end{tabular}




\begin{tabular}{llll} 
Emotional Engagement & Z1 & 0,786 & 0.644 \\
& Z2 & 0,797 & \\
Kepuasan Siswa & Z4 & 0,823 & \\
& Y1 & 0,726 & 0.563 \\
& Y2 & 0,795 & \\
& Y3 & 0,764 & \\
& Y4 & 0,713 & \\
\hline \hline
\end{tabular}

Indikator dapat dikatakan valid apabila AVE $\geq 0.50$ untuk penelitian confirmatory atau exploratory research. Berdasarkan data tersebut, diketahui nilai dari loading dan AVE diatas 0.50. Sehingga item dalam penelitian ini dapat dinyatakan sudah mampu memenuhi uji convergent validity.

Discriminant validity

Discriminant Validity bertujuan untuk mengetahui apakah korelasi variabel terhadap variabel itu sendiri memiliki nilai lebih besar daripada korelasi variabel terhadap variabel yang lain dalam penelitian. Discriminant Validity dapat diketahui dari tabel discriminant validity dan nilai cross loading. Berikut tabel discriminant validity dalam penelitian ini:

Tabel 2. Discriminant Validity

\begin{tabular}{|c|c|c|c|c|}
\hline & $\begin{array}{l}\text { Emotional } \\
\text { Engagemen } \\
t\end{array}$ & $\begin{array}{l}\text { Kepuasan } \\
\text { Siswa }\end{array}$ & $\begin{array}{l}\text { Persepsi } \\
\text { Usefulness } \\
\text { of Platfrom }\end{array}$ & $\begin{array}{l}\text { Sel- } \\
\text { Efficacy }\end{array}$ \\
\hline Emotional Engagement & 0,802 & & & \\
\hline Kepuasan Siswa & 0,693 & o,750 & & \\
\hline $\begin{array}{l}\text { Persepsi Usefulness of } \\
\text { Platfrom }\end{array}$ & 0,562 & 0,638 & $\mathbf{0 , 7 2 9}$ & \\
\hline Self-Efficacy & 0,326 & 0,362 & 0,205 & 0,718 \\
\hline
\end{tabular}

Pada tabel 2 dapat diketahui bahwa nilai loading dari setiap variabel yaitu Emotional Engagement (0.802), Kepuasan Siswa (0.750), Persepsi Usefulness (0.729) dan Self-Efficacy (0.718) lebih besar dari nilai konstruk lainnya. Maka tiap variabel dalam penelitian ini dapat dinyatakan sudah memenuhi discriminant validity. Selain itu discriminant validity dapat dilihat dari hasil cross loading . Berikut tabel hasil cross loading dalam penelitian ini:

Tabel 3. Cross Loading

\begin{tabular}{lllll}
\hline & $\begin{array}{l}\text { Emotional } \\
\text { Engagement }\end{array}$ & $\begin{array}{l}\text { Kepuasan } \\
\text { Siswa }\end{array}$ & $\begin{array}{l}\text { Persepsi } \\
\text { Usefulness } \\
\text { of Platfrom }\end{array}$ & $\begin{array}{l}\text { Self- } \\
\text { Efficacy }\end{array}$ \\
\hline X1.1 & 0,383 & 0,459 & $\mathbf{0 , 7 3 5}$ & 0,134 \\
X1.2 & 0,292 & 0,383 & $\mathbf{0 , 6 1 2}$ & 0,101 \\
X1.3 & 0,465 & 0,531 & $\mathbf{0 , 7 7 5}$ & 0,263 \\
X1.5 & 0,473 & 0,475 & $\mathbf{0 , 7 8 3}$ & 0,082 \\
X2.1 & 0,195 & 0,201 & 0,002 & $\mathbf{0 , 6 8 7}$ \\
X2.2 & 0,182 & 0,262 & 0,119 & $\mathbf{0 , 6 5 1}$ \\
X2.3 & 0,243 & 0,293 & 0,183 & $\mathbf{0 , 7 0 5}$ \\
X2.4 & 0,274 & 0,258 & 0,243 & $\mathbf{0 , 8 0 5}$ \\
X2.5 & 0,260 & 0,275 & 0,149 & $\mathbf{0 , 7 3 5}$ \\
Y1 & 0,576 & $\mathbf{0 , 7 2 6}$ & 0,480 & 0,270 \\
Y2 & 0,500 & $\mathbf{0 , 7 9 5}$ & 0,508 & 0,221 \\
Y3 & 0,466 & $\mathbf{0 , 7 6 4}$ & 0,458 & 0,352 \\
Y4 & 0,528 & $\mathbf{0 , 7 1 3}$ & 0,464 & 0,245 \\
Z1 & $\mathbf{0 , 7 8 6}$ & 0,554 & 0,481 & 0,298 \\
Z2 & $\mathbf{0 , 7 9 7}$ & 0,563 & 0,458 & 0,230 \\
Z4 & $\mathbf{0 , 8 2 3}$ & 0,549 & 0,409 & 0,254 \\
\hline \hline
\end{tabular}

Berdasarkan tabel 3 diatas, menunjukkan bahwa korelasi persepsi usefulness terhadap persepsi usefulness memiliki nilai yang lebih besar daripada nilai korelasi persepsi usefulness terhadap variabel lainnya. Korelasi self-efficacy terhadap self-efficacy memiliki nilai lebih besar daripada nilai korelasi 
Al- Ishlah: Jurnal Pendidikan, June 2021, 13 (1), Pages 617-629

Iffa Masruroh, Jun Surjanti, Nimatush Sholikhah

self-efficacy terhadap variabel lainnya. Hubungan emotional engagement terhadap emotional engagement memiliki nilai korelasi yang lebih besar daripada hubungan emotional engagement terhadap variabel lainnya. Serta korelasi kepuasan siswa terhadap kepuasan siswa memiliki nilai yang lebih besar daripada nilai dari korelasi kepuasan siswa terhadap variabel lainnya. Sehingga dapat diketahui bahwa korelasi variabel terhadap variabel itu sendiri memiliki nilai korelasi yang lebih besar dibandingkan nilai korelasi variabel terhadap variabel lainnya. Sehingga item-item pada penelitian ini telah mampu memenuhi uji discriminant validity.

Cronbach's Alpha dan Composite Reliability

Tabel 4. Cronbach's Alpha dan Composite Reliability

\begin{tabular}{lll}
\hline \hline Variabel & Cronbach's Alpha & Composite Reliability \\
\hline Emotional Engagement & 0,723 & 0,844 \\
Kepuasan Siswa & 0,740 & 0,837 \\
Persepsi Usefulness of Platfrom & 0,706 & 0,818 \\
Self-Efficacy & 0,765 & 0,841 \\
\hline \hline
\end{tabular}

Berdasarkan tabel 4, tiap-tiap item sudah mampu memenuhi syarat yang dilihat dari nilai Cronbach's Alpha yang dimiliki setiap item yaitu $\geq 0.70$. Cronbach's Alpha memiliki standart niai $\geq 0.70$ (Ghozali \& Latan, 2012). Apabila nilai dari Cronbach's Alpha <0.70 maka dapat dilihat dari nilai composite realibility. Hasil olah data menunjukkan nilai composite realibility $\geq 0.70$. Setiap item dari suatu variabel dikatakan reliabel apabila nilai dari composite realibility yaitu $\geq 0.70$ (Wong, 2019). Sehingga tiap-tiap item dalam penelitian ini dapat dikatakan reliabel.

\section{Model Struktural (Inner Model)}

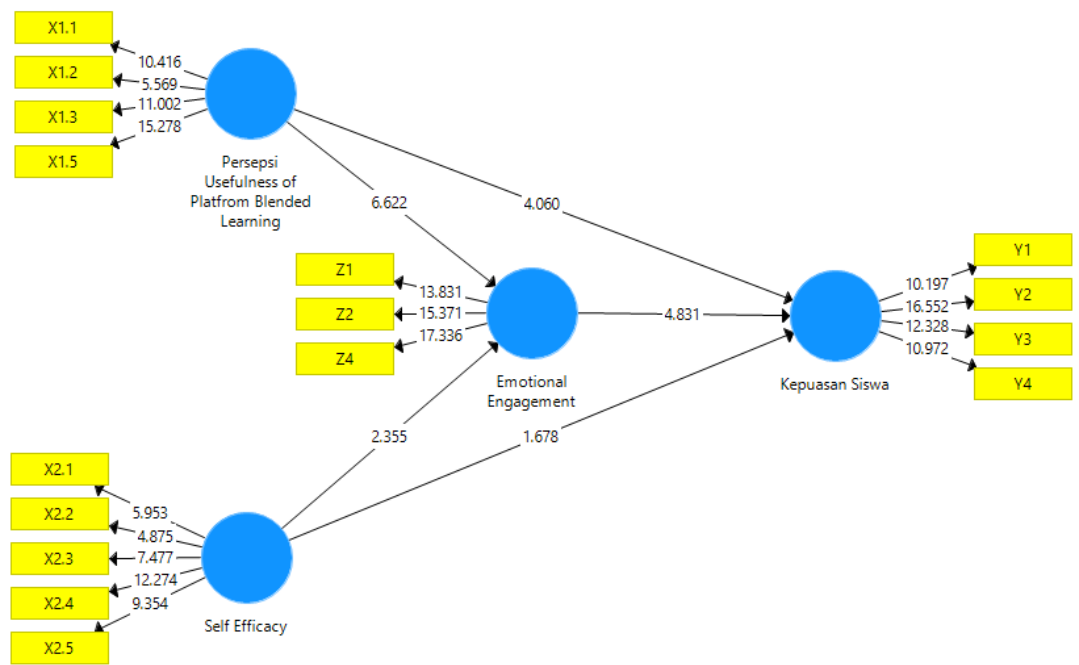

Gambar. 1. Hasil Inner Model

Tabel 5. R-Square

\begin{tabular}{lll}
\hline & $R$ Square & $\begin{array}{l}R \text { Square } \\
\text { Adjusted }\end{array}$ \\
\hline $\begin{array}{l}\text { Emotional Engagement } \\
\text { Kepuasan Siswa }\end{array}$ & 0,362 & 0,346 \\
\hline \hline
\end{tabular}

Nilai $R$-Square $\left(\mathrm{R}^{2}\right)$ menunjukkan seberapa konstruk endogen dipengaruhi oleh konstruk eksogen. Konstruk endogen dapat dikatakan kuat apabila memiliki $R$-Square $\left(\mathrm{R}^{2}\right)$ sebesar 0.67, moderate 0.33 dan lemah 0.19 (Urbach \& Ahleman, 2010). Berdasarkan hasil analisis yang telah dilakukan diperoleh nilai dari $R$-Square (R2) berkisar 0.362- 0.589. Sehingga konstruk endogen dalam penelitian ini yaitu emotional engagement dan kepuasan siswa memiliki $R$-Square (R2) yang moderate. Hal ini menunjukkan bahwa variabel emotional engagement memiliki nilai $R$-Square (R2) sebesar 0.362 atau 36\% dipengaruhi oleh variabel persepsi usefulness dan self-efficacy. Sedangkan $64 \%$ dipengaruhi oleh variabel lainnya diluar penelitian. Nilai $R$-Square (R2) dari kepuasan siswa 
menunjukkan 0.589 atau 58\% dipengaruhi oleh variabel persepsi usefulness, self-efficacy dan emotional engagement. Sedangkan variabel lainnya yang tidak ada dalam penelitian ini berkontribusi dalam mempengaruhi kepuasan siswa sebesar $42 \%$.

Uji kesesuaian model yang digunakan pada penelitian ini yaitu Standardized Root Mean Square Residual (SRMR) karena keseluruhan uji goodness of fit diperdebatkan dalam kegagalannya untuk mengukur valid atau tidaknya suatu model (Wong, 2019). Model penelitian dinyatakan fit apabila nilai dari SRMR < 0.10 dan model dinyatakan tidak fit atau tidak layak apabila nilai SRMR >0.15 (Ghozali \& Latan, 2012). Nilai SRMR dalam penelitian ini menunjukkan 0.095 sehingga dapat dinyatakan model penelitian ini fit atau layak.

Analisis Q-Square (Q2) bertujuan untuk mengetahui indikator dalam model dapat diprediksi secara akurat. Model dapat dinyatakan predictive relavan apabila Q-Square (Q2) memiliki nilai lebih besar dari o (nol) (Ghozali \& Latan, 2015). Nilai Q-Square (Q2) dapat diketahui dari penghitungan sebagai berikut:

$$
\begin{aligned}
\mathrm{Q} 2 & =1-(1-\mathrm{R} 12) \times(1-\mathrm{R} 22) \\
& =1-(1-0.362) \times(1-0.589) \\
& =1-(0.638) \times(0.411) \\
& =0.738
\end{aligned}
$$

Nilai Q-Square (Q2) yang diperoleh dari hasil penghitungan Stone-Geisser Q-Square test yaitu 0.738 yang bernilai lebih besar dari o (nol). Artinya model struktural dalam penelitian ini memiliki prediksi relevansi.

\section{Pengujian Hipotesis}

Tabel 6. Path Coefficient

\begin{tabular}{llllll}
\hline \hline & $\begin{array}{l}\text { Original } \\
\text { Sample (O) }\end{array}$ & $\begin{array}{l}\text { Sample } \\
\text { Mean (M) }\end{array}$ & $\begin{array}{l}\text { Standard } \\
\text { Deviation } \\
\text { (STDEV) }\end{array}$ & $\begin{array}{l}\text { T Statistics } \\
(|\mathrm{O} / \mathrm{STDEV}|)\end{array}$ & P Values \\
\hline $\begin{array}{l}\text { Persepsi Usefulness } \\
\text { Kepuasan Siswa }\end{array}$ & 0,359 & 0,359 & 0,088 & 4,060 & 0,000 \\
$\begin{array}{l}\text { Persepsi Usefulness -> } \\
\text { Emotional Engagement }\end{array}$ & 0,517 & 0,522 & 0,078 & 6,622 & 0,000 \\
$\begin{array}{l}\text { Self-Efficacy } \\
\text { Kepuasan Siswa }->\end{array}$ & 0,144 & 0,151 & 0,086 & 1,678 & 0,047 \\
$\begin{array}{l}\text { Self-Efficacy } \\
\text { Emotional Engagement } \\
\text { Emotional Engagement } \\
->\text { Kepuasan Siswa }\end{array}$ & $0,0,445$ & 0,233 & 0,093 & 2,355 & 0,009 \\
\hline
\end{tabular}

\section{Persepsi Usefulness of Platform Blended Learning Berpengaruh Positif dan Signifikan Terhadap Kepuasan Siswa}

Berdasarkan hasil pengolahan data dapat diketahui bahwa persepsi usefulness of platform blended learning yang dimiliki siswa akan berdampak pada kepuasan siswa dalam menggunakan platform blended learning. Hal ini ditujukan dengan hubungan persepsi usefulness of platform dan kepuasan siswa memiliki arah korelasi yang positif $(\beta=0,359)$ dan signifikan yang dilihat dari nilai $P$ Values sebesar $0,000 \leq$ alpha (0.05). Artinya semakin tinggi persepsi siswa terkait kegunaan dari platform blended learning maka semakin tinggi pula kepuasan siswa dalam menggunakan platform blended learning.

Hasil penelitian menemukan persepsi usefulness of platfrom blended learning memiliki pengaruh yang kuat terhadap kepuasan siswa. Hal ini membuktikan bahwa pentingnya persepsi siswa terkait kegunaan dari platform blended learning dalam belajar Indeks Harga dan Inflasi. Ketika siswa merasa platform blended learning lebih efektif, lebih mudah digunakan, berguna dan dapat 
meningkatkan kinerjanya dalam belajar Indeks Harga dan Inflasi maka dapat meningkatkan kepuasan siswa dalam menggunakan platform blended learning.

Hasil penelitian ini didukung oleh (Al-Azawei et al., 2017), (Alkhateeb \& Abdalla, 2021), (Almarashdeh et al., 2018), (Alomari, El-Kanj, Alshdaifat, \& Topal, 2020), (Binyamin, Rutter, \& Smith, 2017), (Cigdem \& Ozturk, 2016), (Featherman, Thatcher, Wright, \& Zimmer, 2011), (Islam \& Azad, 2015) dan (Mouakket \& Bettayeb, 2015) yang dalam penelitiannya juga menemukan bahwa persepsi usefulness of platform berpengaruh secara positif dan signifikan terhadap kepuasan siswa. Namun hasil penelitian ini menentang penelitian dari (Gao et al., 2020) yang menemukan persepsi usefulness of platform tidak berpengaruh terhadap kepuasan siswa.

\section{Persepsi Usefulness of Platform Blended Learning Berpengaruh Positif dan Signifikan terhadap Emotional Engagement}

Berlandaskan hasil penelitian ditemukan bahwa persepsi usefulness of platfrom blended learning berpengaruh signifikan dan memiliki arah yang positif $(\beta=0,517)$ dan signifikan $(P$-Value= $0,000 \leq 0.05$ ). Sehingga dapat diartikan bahwa apabila siswa memiliki persepsi usefulness of platform blended learning yang tinggi maka emotional engagement juga meningkat. Demikian dapat disimpulkan bahwa tingginya persepsi usefulness siswa kelas XI IPS SMA Negeri 14 Surabaya terhadap platform blended learning mampu meningkatkan emotional engagement dalam menggunakan platform blended learning.

Konsisten dengan penelitian (Gao et al., 2020) yang menghasilkan persepsi usefulness of platform blended learning berpengaruh positif dan signifikan terhadap emotional engagement. Gao juga menyatakan bahwa ketika siswa berpendapat bahwa platform blended learning menarik, lebih bernilai, lebih bermanfaat dan lebih mudah digunakan maka siswa akan menunjukkan reaksi emosional yang positif terhadap pembelajaran. Persepsi usefulness sebagai penentu utama dalam emotional engagement yang positif dalam pembelajaran (Gao et al., 2020).

\section{Self-Efficacy Berpengaruh Positif dan Signifikan Terhadap Kepuasan Siswa}

Terdapat pengaruh yang positif dan signifikan antara self-efficacy terhadap kepuasan siswa. Hal ini diketahui dengan melihat hasil koefisien jalur yang memiliki arah positif $(\beta=0,144)$ dan tingkat signifikansinya $(P$-value $=0,047 \leq 0.50)$. Arah yang positif memiliki arti yang berbanding lurus sehingga dapat ditarik kesimpulan bahwa apabila siswa memiliki self-efficacy tinggi dalam menggunakan platform blended learning maka akan meningkatkan kepuasan siswa. Terbukti bahwa siswa yang memiliki tingkat percaya diri dan keterampilan dalam menggunakan LMS yang tinggi cenderung mempelajari sistem baru sehingga dapat mempengaruhi kepuasan siswa. Mengingat bahwa selfefficacy memiliki peran penting dalam menentukan efektivitas pembelajaran dengan menggunakan platform (Surjanti et al., 2020).

Berdasarkan hasil penelitian diketahui sebagian siswa kelas XI IPS SMA Negeri 14 Surabaya merasa percaya diri dalam menggunakan platform blended learning dan mampu menyelesaikan tugas Indeks Harga dan Inflasi melalui platform blended learning. Semakin siswa merasa percaya diri dalam menggunakan platform blended learning akan berdampak pada tingginya rasa puas siswa terhadap platform blended learning. Hasil penelitian ini mendukung penelitian sebelumnya yaitu (Alkhateeb \& Abdalla, 2021); (Almahamid \& Abu Rub, 2011); (Alshare, Freeze, Lane, \& Wen, 2011) dan (Gao et al., 2020). Selain itu juga mendukung penelitian (Prifti, 2020) yang menemukan hubungan kuat antara self-efficacy dengan kepuasan siswa. Namun hasil penelitian ini tidak sejalan dengan penelitian (Cigdem \& Ozturk, 2016) dan (Kuo et al., 2014).

Hasil penelitian ini menunjukkan self-efficacy memiliki nilai korelasi yang kecil dibandingkan variabel lainnya bahkan hampir tidak memiliki korelasi. Penyebabnya yaitu sebesar $71 \%$ siswa telah menggunakan platform blended learning kurang dari 1 tahun yaitu kurang lebih 11 bulan. Sementara siswa yang tergolong generasi $\mathrm{Z}$ ini telah terbiasa menggunakan teknologi pembelajaran. Sehingga memungkinkan tingkat kepercayaan siswa dalam menggunakan platform berada pada tingkat rata-rata yang sesuai dengan pendapat (Kuo et al., 2014). 


\section{Self-Efficacy Berpengaruh Positif dan Signifikan Terhadap Emotional Engagement}

Hasil penelitian membuktikan bahwa hubungan yang positif $(\beta=0,220)$ dan signifikan $(P$-value $=$ $0,009 \leq 0.50)$ antara self-efficacy dengan emotional engagement. Hal ini memiliki arti self-efficacy berdampak pada emotional engagement yang dimiliki siswa. Diketahui arah hubungan yang positif menunjukkan bahwa self-efficacy yang tinggi dapat meningkatkan emotional engagement. Siswa kelas XI IPS SMA Negeri 14 Surabaya yang memiliki kepercayaan akan keterampilannya dalam mengoperasikan platform blended learning cenderung melibatkan emosi positif. Emotional engagement yang positif dapat memberikan energi yang positif dalam belajar. Sehingga mampu meningkatkan kinerjanya dalam belejar Indeks Harga dan Inflasi.

Penelitian ini mendukung hasil penelitian dari (Sahni, 2019) yang menemukan adanya hubungan self-efficacy dengan emotional engagement. Konsisten dengan penelitian (Pellas, 2014) yang menemukan adanya hubungan yang positif dan signifikan antara self-efficacy dengan emotional engagement. Siswa yang memiliki self-efficacy tinggi cenderung lebih mudah mengikuti proses pembelajaran (Bates \& Khasawneh, 2007) dengan emosional yang positif.

\section{Emotional Engagement Berpengaruh Positif dan Signifikan Terhadap Kepuasan Siswa}

Berdasarkan hasil penelitian diperoleh hubungan yang positif dan signifikan antara emotional engagement dengan kepuasan siswa. Diketahui nilai koefisien jalur sebesar 0.444 dan $p$-value sebesar $0,000<0.5$. Apabila emotional engagement yang tinggi maka dapat meningkatkan kepuasan siswa. Siswa kelas XI IPS SMA Negeri 14 Surabaya memiliki emotional engagement yang tinggi sehingga kepuasannnya dalam menggunakan platform blended learning juga tinggi. Siswa cenderung melibatkan emotional engagement akan merasa tertarik, senang, dan menikmati pembelajaran dengan platform blended learning. Sehingga hal ini mampu membuat siswa merasa puas dengan platform blended learning.

Hasil penelitian ini sejalan dengan penelitian dari (Gao et al., 2020) yang menemukan emotional engagement berpengaruh positif dan signifikan terhadap kepuasan siswa. Menurut Gao yang berpendapat bahwa semakin besar siswa merasa tertarik dengan platform blended learning maka semakin besar siswa mempunyai perasaan yang positif terhadap pembelajaran. Perasaan yang posiif berdampak pada kepuasan siswa. Pendapat ini juga konsisten dengan penelitian yang dilakukan oleh (Bailey \& Morais, 2005) dan (Filak \& Sheldon, 2008).

Tabel 7. Specific Indirect

\begin{tabular}{|c|c|c|c|c|c|}
\hline & $\begin{array}{l}\text { Original } \\
\text { Sample }(\mathrm{O})\end{array}$ & $\begin{array}{l}\text { Sample } \\
\text { Mean (M) }\end{array}$ & $\begin{array}{l}\text { Standard } \\
\text { Deviatio } \\
n \\
\text { (STDEV) }\end{array}$ & $\begin{array}{l}\text { T Statistics } \\
(|\mathrm{O} / \mathrm{STDEV}| \\
)\end{array}$ & P Values \\
\hline $\begin{array}{l}\text { Persepsi Usefulness of Platfrom -> } \\
\text { Emotional Engagement -> } \\
\text { Kepuasan Siswa }\end{array}$ & 0,230 & 0,233 & 0,066 & 3,505 & 0,000 \\
\hline $\begin{array}{l}\text { Self-Efficacy } \quad->\quad \text { Emotional } \\
\text { Engagement -> Kepuasan Siswa }\end{array}$ & 0,098 & 0,102 & 0,044 & 2,206 & 0,014 \\
\hline
\end{tabular}

\section{Emotional Engagement Memediasi Persepsi Usefulness of Platform Blended Learning terhadap Kepuasan Siswa Secara Positif dan Signifikan}

Berdasarkan hasil penelitian menemukan emotional engagement dapat menjadi mediasi secara parsial antara persepsi usefulness of platform blended learning dan kepuasan siswa. Dilihat dari hubungan langsung antara persepsi usefulness of platform dengan kepuasan siswa yang berpengaruh signifikan dan arahnya positif. Serta hubungan tidak langsung antara persepsi usefulness of platform dengan kepuasan siswa yang memiliki korelasi positif $(\beta=0,230)$ dan signifikan ( $P$-Values $=0,000$ $\leq 0.05$ ). Artinya ada atau tidaknya emotional engagement, persepsi usefulness tetap berpengaruh terhadap kepuasan siswa. 
Siswa kelas XI IPS SMA Negeri 14 Surabaya yang memiliki persepsi bahwa platform blended learning berguna dalam menunjang kegiatan pembelajaran maka siswa akan cenderung terlibat secara emosional yang positif. Siswa yang menggunakan platform blended learning dengan emosional yang positif maka dapat meningkatkan kepuasan siswa. Hasil penelitian ini mendukung (Gao et al., 2020) dalam penelitiannya menemukan pengaruh persepsi usefulness of platform blended learning terhadap kepuasan siswa melalui emotional engagement.

\section{Emotional Engagement Memediasi Pengaruh Self-Efficacy Terhadap Kepuasan Siswa Secara Positif dan Signifikan}

Berlandaskan hasil dari penelitian ditemukan adanya pengaruh self-efficacy terhadap kepuasan siswa yang dimediasi oleh emotional engagement secara parsial. Hal ini terjadi karena adanya pengaruh langsung antara self-efficacy dengan kepuasan siswa secara positif dan signifikan sedangkan pengaruh tidak langsung memiliki hubungan yang positif $(\beta=0,098)$ dan signifikan $(P$-Values $=0,014$ $\leq 0.05)$

Self-efficacy yang tinggi tidak hanya meningkatkan emotional engagement (Sahni, 2019) namun juga meningkatkan kepuasan siswa (Gao et al., 2020) secara bersamaan. Ketika siswa kelas XI IPS di SMA Negeri 14 Surabaya merasa percaya diri bisa menggunakan platform blended learning maka dapat meningkatkan keterlibatan secara emosional yang positif dan kepuasan siswa dalam menggunakan blended learning. Emotional engagement menjembatani hubungan antara self-efficacy dan kepuasan siswa. Namun tanpa adanya emotional engagement, self-efficacy tetap berpengaruh terhadap kepuasan siswa dengan memiliki nilai korelasi yang paling rendah daripada variabel lainnya. Siswa kelas XI IPS di SMA Negeri 14 harus memiliki emotional engagement yang tinggi agar self-efficacy dapat mempengaruhi kepuasannya.

\section{SIMPULAN}

Persepsi usefulness of platfrom, self-efficacy dan emotional engagement berdampak pada kepuasan siswa. Apabila siswa memiliki persepsi usefulness, self-efficacy dan emotional engagement yang tinggi maka kepuasan dalam menggunakan platform juga meningkat. Selain itu emotional engagament mampu memediasi secara parsial antara persepsi usefulness terhadap kepuasan siswa. Hasil penelitian yang menjadi pembaruan dalam penelitian ini yaitu ditemukannya pengaruh selfefficacy terhadap kepuasan siswa yang dimediasi oleh emotional engegament. Hal ini menunjukkan bahwa emotional engagement yang dimiliki siswa mampu menjembatani pengaruh persepsi usefulness dan self-efficacy terhadap kepuasan siswa. Dengan demikian, guru harus memperhatikan variabel persepsi usefulness of platform, self-efficacy dan emotional engagement agar kepuasan siswa dalam menggunakan platform blended learning dapat meningkat. Sehingga dapat meningkatkan kualitas pembelajaran dan hasil belajar siswa. Penelitian ini memiliki banyak kekurangan dikarenakan keterbatasan yang dimiliki penulis. Sehingga untuk penelitian selanjutnya, diharapkan dapat mengembangkan penelitian ini dengan menambah variabel independen agar hasil menjadi lebih baik. Serta dapat memperluas sampel penelitian yang digunakan agar hasil penelitian dapat digeneralisasikan.

\section{DAFTAR PUSTAKA}

Akyol, Z., \& Garrison, D. R. (2008). the Development of a Community of Inquiry Over Time in an Online Course: Understanding the Progression and Integration of Social, Cognitive and Teaching Presence. Online Learning, 12(3). http://doi.org/10.24059/olj.v12i3.72

Al-Azawei, A., Parslow, P., \& Lundqvist, K. (2017). Investigating the effect of learning styles in a blended e-learning system: An extension of the technology acceptance model (TAM). Australasian Journal of Educational Technology, 33(2), 1-23. http://doi.org/10.14742/ajet.2741

Al-Rahmi, W. M., Othman, M. S., \& Yusuf, L. M. (2015). Exploring the factors that affect student satisfaction through using E-learning in Malaysian higher education institutions. Mediterranean Journal of Social Sciences, 6(4S1), 299-310. http://doi.org/10.5901/mjss.2015.v6n4s1p299

Alkhateeb, M. A., \& Abdalla, R. A. (2021). Factors influencing student satisfaction towards using learning management system moodle. International Journal of Information and Communication Technology Education, 17(1), 138-153. http://doi.org/10.4018/IJICTE.2021010109 
Almahamid, S., \& Abu Rub, F. (2011). Factors that determine continuance intention to use e-learning system: an empirical investigation. International Conference on Telecommunication Technology and Applications Proc. of CSIT, 5, 242-246. Retrieved from http://www.ipcsit.net/vol5/43ICCCM2011-A20017.pdf

Almarashdeh, I. (2016). Sharing instructors experience of learning management system: A technology perspective of user satisfaction in distance learning course. Computers in Human Behavior, 63, 249-255. http://doi.org/10.1016/j.chb.2016.05.013

Almarashdeh, I., Alsmadi, M. K., Jaradat, G., Althunibat, A., Albahussain, S. A., Qawqzeh, Y., ... Eldaw, K. E. (2018). Looking inside and outside the system: Examining the factors influencing distance learners satisfaction in learning management system. Journal of Computer Science, 14(4), 453465. http://doi.org/10.3844/jcssp.2018.453.465

Alomari, M. M., El-Kanj, H., Alshdaifat, N. I., \& Topal, A. (2020). A framework for the impact of human factors on the effectiveness of learning management systems. IEEE Access, 8, 23542-23558. http://doi.org/10.1109/ACCESS.2020.2970278

Alshare, K. A., Freeze, R. D., Lane, P. L., \& Wen, H. J. (2011). The Impacts of System and Human Factors on Online Learning Systems Use and Learner Satisfaction. Decision Sciences Journal of Innovative Education, 9(3), 437-461. http://doi.org/10.1111/j.1540-4609.2011.00321.x

Andrade, M. S., Miller, R. M., Kunz, M. B., \& Ratliff, J. M. (2019). Online learning in schools of business: The impact of quality assurance measures. Journal of Education for Business, o(o), 1-8. http://doi.org/10.1080/08832323.2019.1596871

Bailey, K. D., \& Morais, D. B. (2005). Exploring the use of blended learning in tourism education. Journal of Teaching in Travel and Tourism, 4(4), 23-36. http://doi.org/10.1300/J172v04no4_02

Bates, R., \& Khasawneh, S. (2007). Self-efficacy and college students' perceptions and use of online learning systems. Computers in Human Behavior, 23(1), 175-191. http://doi.org/10.1016/j.chb.2004.04.004

Binyamin, S., Rutter, M., \& Smith, S. (2017). Factors influencing the students' use of learning management systems: A case study of King Abdulaziz University. Proceedings of the International Conference on E-Learning, ICEL, (June), 289-297.

Bolliger, D. U., Inan, F. A., \& Wasilik, O. (2014). Development and validation of the online instructor satisfaction measure (OISM). Educational Technology and Society, 17(2), 183-195.

Chen, W. S., \& Tat Yao, A. Y. (2016). An Empirical Evaluation of Critical Factors Influencing Learner Satisfaction in Blended Learning: A Pilot Study. Universal Journal of Educational Research, 4(7), 1667-1671. http://doi.org/10.13189/ujer.2016.040719

Cigdem, H., \& Ozturk, M. (2016). Factors Affecting Student s ' Behavioral Intention to Use LMS at a Turkish Post-Secondary Vocational School, 17(3).

Compeau, D. R., \& Higgins, C. A. (1995). ASTM E2368-10, Standard Practice for Strain Controlled Thermomechanical Fatigue Testing. MIS Quarterly, 19(2), 189-211. Retrieved from https://www.astm.org/Standards/E2368.htm

Davis, F. D. (1989). Perceived usefulness, perceived ease of use, and user acceptance of information technology. MIS Quarterly: Management Information Systems, 13(3), 319-339. http://doi.org/10.2307/249008

DeLone, W. H., \& McLean, E. R. (1992). Information systems success: The quest for the dependent variable. Information Systems Research, 3(1), 60-95. http://doi.org/10.1287/isre.3.1.6o

Eom, S. B. (2014). Understanding e-learners' satisfaction with learning management systems. Bulletin of the Technical Committee on Learning Technology, 16(2-3), 10-13.

Featherman, M., Thatcher, J., Wright, R. T., \& Zimmer, J. C. (2011). The Role of Perceived System Quality as Educators' Motivation to Continue E-learning System Use. AIS Transactions on Human-Computer Interaction, 3(1), 1-25.

Filak, V. F., \& Sheldon, K. M. (2008). Teacher support, student motivation, student need satisfaction, and college teacher course evaluations: Testing a sequential path model. Educational Psychology, 28(6), 711-724. http://doi.org/10.1080/01443410802337794

Gao, B. W., Jiang, J., \& Tang, Y. (2020). The effect of blended learning platform and engagement on students' satisfaction-- the case from the tourism management teaching. Journal of Hospitality, $\begin{array}{llll}\text { Leisure, Sport and Tourism } & \text { Education, } 27 \text { (September), } & 100272 .\end{array}$ http://doi.org/10.1016/j.jhlste.2020.100272 
Ghazal, S., Aldowah, H., Umar, I., \& Bervell, B. (2018). Acceptance and satisfaction of learning management system enabled blended learning based on a modified DeLone-McLean information system success model. International Journal of Information Technology Project Management, 9(3), 52-71. http://doi.org/10.4018/IJITPM.2018070104

Ghozali, I., \& Latan, H. (2012). Partial least squares : konsep, teknik dan aplikasi SmartPLS 2.o M3 untuk penelitian empiris / Hengky Latan, Imam Ghozali. Semarang: Badan Penerbit Universitas Diponegoro.

Ghozali, I., \& Latan, H. (2015). Partial least squares: Konsep, teknik, dan aplikasi menggunakan program smart PLS 3.0 (2nd ed.). Semarang: Universitas Diponegoro.

Halverson, L. R., \& Graham, C. R. (2019). Learner engagement in blended learning environments: A conceptual framework. Online Learning Journal, 23(2), 145-178. http://doi.org/10.24059/olj.v23i2.1481

Ibrahim Abbas, Z. (2018). Blended Learning and Student Satisfaction: An Investigation into an EAP Writing Course. Advances in Language and Literary Studies, 9(1), 102. http://doi.org/10.7575/aiac.alls.v.9n.1p.102

Igbaria, M., \& Iivari, J. (1995). The effects of self-efficacy on computer usage. Omega, 23(6), 587-605. http://doi.org/10.1016/0305-0483(95)00035-6

Islam, A. K. M. N., \& Azad, N. (2015). Satisfaction and continuance with a learning management system. The International Journal of Information and Learning Technology, 32(2), 109-123. http://doi.org/10.1108/ijilt-09-2014-0020

Jung, I., Choi, S., Lim, C., \& Leem, J. (2002). Effects of different types of interaction on learning achievement, satisfaction and participation in web-based instruction. Innovations in Education and Teaching International, 39(2), 153-162. http://doi.org/10.1080/14703290252934603

Kucuk, S., \& Richardson, J. C. (2019). A structural equation model of predictors of online learners' engagement and satisfaction. Online Learning Journal, 23(2), 196-216. http://doi.org/10.24059/olj.v23i2.1455

Kuo, Y. C., Walker, A. E., Belland, B. R., Schroder, K. E. E., \& Kuo, Y. T. (2014). A case study of integrating interwise: Interaction, internet self-efficacy, and satisfaction in synchronous online learning environments. International Review of Research in Open and Distance Learning, 15(1), 161-181. http://doi.org/10.19173/irrodl.v15i1.1664

Lin, H. C., Chiu, Y. H., Chen, Y. J., Wuang, Y. P., Chen, C. P., Wang, C. C., ... Ho, W. H. (2017). Continued use of an interactive computer game-based visual perception learning system in children with developmental delay. International Journal of Medical Informatics, 107(July), 76-87. http://doi.org/10.1016/j.ijmedinf.2017.09.003

Manwaring, K. C. (2017). Emotional and Cognitive Engagement in Higher Education Classrooms. Retrieved from https://scholarsarchive.byu.edu/cgi/viewcontent.cgi?article $=7636 \&$ context=etd

Mouakket, S., \& Bettayeb, A. M. (2015). Investigating the factors influencing continuance usage intention of Learning management systems by university instructors: The Blackboard system case. International Journal of Web Information Systems, 11(4), 491-509. http://doi.org/10.1108/IJWIS-03-2015-0008

Ohliati, J., \& Abbas, B. S. (2019). Measuring students satisfaction in using learning management system. International Journal of Emerging Technologies in Learning, 14(4), 180-189. http://doi.org/10.3991/ijet.v14.io4.9427

Pellas, N. (2014). The influence of computer self-efficacy, metacognitive self-regulation and self-esteem on student engagement in online learning programs: Evidence from the virtual world of Second Life. Computers in Human Behavior, 35, 157-170. http://doi.org/10.1016/j.chb.2014.02.048

Prifti, R. (2020). Self-efficacy and student satisfaction in the context of blended learning courses. Open Learning, $o(0), 1-15$. http://doi.org/10.1080/02680513.2020.1755642

Sahni, J. (2019). Applying technology to enhance student satisfaction and engagement: Case of business students. TEM Journal, 8(2), 623-629. http://doi.org/10.18421/TEM82-41

Seddon, P. B. (1997). A Respecification and Extension of the DeLone and McLean Model of IS Succes. Information Systems Research, 8, 240-253.

Skinner, E. A., \& Belmont, M. J. (1993). Motivation in the Classroom: Reciprocal Effects of Teacher Behavior and Student Engagement Across the School Year. Journal of Educational Psychology, 85(4), 571-581. http://doi.org/10.1037/0022-0663.85.4.571

Surjanti, J., Sakti, N. C., \& Fitrayati, D. (2020). Virtual-based learning attitude: The mediator of individual factors on intention to use. International Journal of Innovation, Creativity and Change, 12(4), 165-186. 
UNICEF. (2020). Rencana Kembali Ke Sekolah di Masa Covid-19.

Urbach, N., \& Ahleman, F. (2010). Structural equation modeling in information systems research using Partial Least Squares. Journal Of Information Technology Theory And Application, 11(2), 5-40.

Wolverton, C. C., Guidry Hollier, B. N., \& Lanier, P. A. (2020). The impact of computer self efficacy on student engagement and group satisfaction in online business courses. Electronic Journal of ELearning, 18(2), 175-188. http://doi.org/10.34190/EJEL.20.18.2.006

Wong, K. K.-K. (2019). Mastering Partial Least Squares Structural Equation Modeling (PLS-SEM) with SmartPLS in 38 Hours. Bloomington.

Wu, J., \& Liu, W. (2013). An Empirical Investigation of the Critical Factors Affecting Students' Satisfaction in EFL Blended Learning. Journal of Language Teaching and Research, 4(1), 176185. http://doi.org/10.4304/jltr.4.1.176-185

Xiao, J., \& Wilkins, S. (2015). The effects of lecturer commitment on student perceptions of teaching quality and student satisfaction in Chinese higher education. Journal of Higher Education Policy and Management, 37(1), 98-110. http://doi.org/10.1080/1360080X.2014.992092 